\title{
ESTILOS DE APRENDIZAGEM À LUZ DOS POSTULADOS DE KOLB: \\ UMA ANÁLISE DAS PRÁTICAS NOS CURSOS DE ADMINISTRAÇÃO, CIÊNCIAS CONTÁBEIS E SERVIÇO SOCIAL EM INSTITUIÇÕES DE ENSINO SUPERIOR DO ALTO SERTÃO PARAIBANO.
}

\author{
Edvanilza Luzia Leite Dos Santos, UFCG, \\ vanmellcz@gmail.com. \\ Gianinni Martins Pereira Cirne, UFCG, \\ gianinni.martins@gmail.com \\ Lúcia Silva Albuquerque, UFCG, \\ luciasalbuquerque@gmail.com
}

\begin{abstract}
RESUMO: Essa pesquisa teve como objetivo a influência dos estilos de aprendizagem nos discentes. A coleta de dados ocorreu por meio de questionário objetivo dividido em duas seções onde a primeira tratava do perfil do aluno e a segunda a identificação dos estilos de aprendizagem através do Inventário de Estilos de Aprendizagem de Kolb. Para análise e para a relação entre os estilos de aprendizagem e sua influência sobre o rendimento acadêmico foram criadas duas hipóteses . A amostra contou com a participação de 621 alunos distribuídos nas quatro Instituições de Ensino Superiores desta pesquisa. $\mathrm{Na}$ análise não houve indícios que o rendimento acadêmico dos alunos foi influenciado pelos seus estilos de aprendizagem, entretanto é preciso ter em mente que o reconhecimento desses estilos é um fator importante para subsidiar os professores em suas estratégias de ensino para o alcance do objetivo educacional que é a aprendizagem, como também é importantes para os próprios alunos o conhecimento do seu estilo predominante.
\end{abstract}

Palavras-Chaves: Estilos de Aprendizagem. Estratégias de Ensino.Educação. Discentes.

\section{LITERATURE STYLES IN THE LIGHT OF KOLB POSTULATES: AN ANALYSIS OF THE PRACTICES IN THE COURSES OF ADMINISTRATION, ACCOUNTING SCIENCES AND SOCIAL SERVICE IN HIGH SCHOOL INSTITUTIONS OF THE HIGH PARAIBANO SERTÃO.}

\section{ABSTRACT}

This research had as objective the influence of the learning styles in the students. The data collection was done through an objective questionnaire divided into two sections where the first dealt with the student profile and the second the identification of learning styles through the Kolb Learning Styles Inventory. For analysis and for the relationship between learning styles and their influence on academic achievement, two hypotheses were created. The sample 
had the participation of 621 students distributed in the four Higher Education Institutions of this research. In the analysis there was no evidence that the academic performance of the students was influenced by their learning styles, however it is necessary to keep in mind that the recognition of these styles is an important factor to subsidize teachers in their teaching strategies to reach the educational objective that Is learning, but it is also important for the students themselves to know their predominant style.

Keywords: Learning Styles. Teaching Strategies. Education. Students.

\section{ESTILOS DE APRENDIZAJE A LA LUZ DE LOS POSTULADOS DE KOLB: UN ANÁLISIS DE LAS PRÁCTICAS EN LOS CURSOS DE ADMINISTRACIÓN, CIENCIAS CONTABLES Y SERVICIO SOCIAL EN INSTITUCIONES DE ENSEÑANZA SUPERIOR DEL ALTO SERTÓN PARAIBANO. RESUMEN}

Esta investigación tuvo como objetivo la influencia de los estilos de aprendizaje en los discentes. La recolección de datos ocurrió por medio de cuestionario objetivo dividido en dos secciones donde la primera trataba del perfil del alumno y la segunda la identificación de los estilos de aprendizaje a través del Inventario de Estilos de Aprendizaje de Kolb. Para el análisis y la relación entre los estilos de aprendizaje y su influencia sobre el rendimiento académico se crearon dos hipótesis. La muestra contó con la participación de 621 alumnos distribuidos en las cuatro Instituciones de Enseñanza Superior de esta investigación. En el análisis no hubo indicios de que el rendimiento académico de los alumnos fue influenciado por sus estilos de aprendizaje, sin embargo hay que tener en cuenta que el reconocimiento de esos estilos es un factor importante para subsidiar a los profesores en sus estrategias de enseñanza para el alcance del objetivo educativo que, Es el aprendizaje, como también es importante para los propios alumnos el conocimiento de su estilo predominante.

Palabras clave: Estilos de Aprendizaje.Estrategias de Enseñanza.Educación. Discentes.

\section{INTRODUÇÃO}

Dentre as variadas ferramentas utilizadas para identificar os estilos de aprendizagem existentes na literatura atual será utilizado neste trabalho o Learning Style Inventory - LSI (Inventário de Estilos de Aprendizagem) desenvolvido pelo professor e psicólogo David Kolb considerado por autores como Coffield, Moseley e Ecclestone (2004) como um dos mais influentes na atualidade, sendo inclusive fonte de inspiração para outros modelos posteriores.

O Inventário de Estilos de Aprendizagem desenvolvido por Kolb em 1984 foi criado com o objetivo de identificar nos alunos seus estilos de aprendizagem de forma a conhecer 
suas diferenças e semelhanças e a partir daí identificar as formas de perceber e de processar o conhecimento desses alunos, sendo também aplicado em outros campos como em processos de desenvolvimento pessoal, orientação profissional, estudos sobre profissionais de determinada área de atuação dentre outras.

Quando uma pessoa está no processo de adquirir conhecimento ele opta pela forma que mais o deixará confortável e o ciclo de aprendizagem se inicia. O ciclo proposto por Kolb possui quatro quadrantes que representam as características da aprendizagem e foram conceituadas por Kolb como: Divergente, Assimilador, Convergente e Acomodador (SOUZA KOLB E KOLB, 2005). Cada indivíduo pode combinar dois ou mais estilos de aprendizagem mesmo que exista um estilo que predomine sobre os demais, através da identificação de quais são as vantagens e desvantagens de cada um dos estilos.

\section{REFERENCIAL TEÓRICO}

\subsection{Estilos de aprendizagem}

Existem inúmeras maneiras distintas de aprender, cada ser humano utiliza uma forma diversa de aceitação e processamento das novas informações. Neste sentido percebe-se que o processo de aprendizagem é algo que ocorre de forma interna em cada individuo e exatamente por isso que existirão formas divergentes de aprender, porém a finalidade é a mesma para todos "adquirir e assimilar conhecimento", mesmo que sejam seguidos passos totalmente distintos e para esses diferentes passos surge o chamado Estilo de Aprendizagem (OLIVEIRA, 2012). 
Quadro 1 - Estilo de ensino para os tipos de estilos de aprendizagem

\begin{tabular}{|c|c|c|}
\hline \multicolumn{2}{|r|}{ ALUNOS } & PROFESSORES \\
\hline $\begin{array}{l}\text { Experiência } \\
\text { Concreta }\end{array}$ & $\begin{array}{l}\text { Divergentes: } \\
\text { - Integram experiência com seus próprios } \\
\text { valores e sentimentos; } \\
\text { - Preferem ouvir e partilhar idéias, } \\
\text { aprendendo pela experiência concreta e } \\
\text { observação reflexiva; } \\
\text { - Criativos e inovadores têm facilidade } \\
\text { para propor alternativas, reconhecer } \\
\text { problemas e compreender pessoas; } \\
\text { - Gostam de saber o valor do que irão } \\
\text { aprender; } \\
\text { - Sua questão preferida é: Por quê? }\end{array}$ & $\begin{array}{l}\text { Motivador: } \\
\text { - Visam o desenvolvimento pessoal dos } \\
\text { alunos; } \\
\text { - Altamente motivadores, tendem a } \\
\text { desenvolver bom relacionamento com } \\
\text { seus alunos; } \\
\text { - Procuram desenvolver a cooperação e } \\
\text { a discussão de valores e significados; } \\
\text { - Gostam de engajar os alunos em } \\
\text { discussão sobre a vida profissional e } \\
\text { social; } \\
\text { A estratégia de ensino envolve } \\
\text { questionamento e discussão em sala } \\
\text { de aula. }\end{array}$ \\
\hline $\begin{array}{c}\text { Observação } \\
\text { Reflexiva }\end{array}$ & $\begin{array}{l}\text { Assimiladores: } \\
\text { - Integram a experiência com } \\
\text { conhecimentos já existentes; } \\
\text { - São conceitualizadores, utilizam a } \\
\text { dedução para resolver problemas; } \\
\text { - Trabalham bem com muitos detalhes e } \\
\text { dados, dando-lhes uma organização } \\
\text { lógica; } \\
\text { - Procuram assimilar novas idéias e } \\
\text { pensamentos; } \\
\text { - São mais interessados pela lógica de } \\
\text { uma idéia do que pelo seu valor prático; } \\
\text { - Sua questão favorita: O quê? }\end{array}$ & $\begin{array}{l}\text { Expositor: } \\
\text { - Visam à transmissão de } \\
\text { conhecimento; } \\
\text { - Na sala de aula ele é a autoridade; } \\
\text { - Livros, textos são escritos por eles e } \\
\text { devem ser seguidos rigorosamente; } \\
\text { - A estratégia de ensino é tradicional } \\
\text { (aula expositiva). }\end{array}$ \\
\hline $\begin{array}{l}\text { Conceituação } \\
\text { Abstrata }\end{array}$ & $\begin{array}{l}\text { Convergentes: } \\
\text { - Integram teoria e prática; } \\
\text { - Utilizam tanto a abstração como o senso } \\
\text { comum na aplicação prática das idéias e } \\
\text { teorias; } \\
\text { - Gostam de resolver problemas práticos } \\
\text { e tem bom desempenho nos testes } \\
\text { convencionais; } \\
\text { - Procuram sempre as soluções ótimas } \\
\text { - } \quad \text { combinam a dedução e a indução na } \\
\text { - Solução de problemas; } \\
\text { Sua questão favorita: como? }\end{array}$ & $\begin{array}{l}\text { Tutor: } \\
\text { - Visam à produtividade e a } \\
\text { competência; } \\
\text { - Procuram ensinar as habilidades } \\
\text { necessárias para ser um bom } \\
\text { engenheiro; } \\
\text { - São altamente independentes e } \\
\text { querem que seus alunos o sejam; } \\
\text { - A estratégia de ensino combina aula } \\
\text { formal com laboratório e atividade } \\
\text { extraclasse. }\end{array}$ \\
\hline $\begin{array}{c}\text { Experimentaçã } \\
\text { o Ativa }\end{array}$ & $\begin{array}{l}\text { Acomodadores } \\
\text { - Integram experiência com aplicação e } \\
\text { fazem imediata aplicação da nova } \\
\text { experiência; } \\
\text { - Utilizam a indução na resolução do } \\
\text { problema; } \\
\text { Aprender por ensino e erro e } \\
\text { freqüentemente descobrem o novo }\end{array}$ & $\begin{array}{l}\text { Inovador } \\
\text { - } \quad \text { Encorajam a aprendizagem } \\
\text { experimental e a autodescoberta; } \\
\text { - } \quad \text { São estimuladores e dramáticos; } \\
\text { - } \quad \text { Procuram expandir os limites } \\
\text { intelectuais de seus alunos; } \\
\text { - A estratégia de ensino envolve } \\
\text { variados métodos e técnicas, de }\end{array}$ \\
\hline
\end{tabular}

Revista de Pesquisa Interdisciplinar, Cajazeiras, n. 2, suplementar, p. 394 - p. 399, set. de 2017. 


\begin{tabular}{|l|l|l|}
\hline & $\begin{array}{l}\text { conhecimento sem a ajuda do professor; } \\
\text { Altamente ativos e criativos adaptam-se } \\
\text { facilmente às novas situações; }\end{array}$ & acordo com a necessidade. \\
• Independentes, lideres naturais; & \\
- Sua questão favorita: E se? & \\
\hline
\end{tabular}

Fonte: Elaboração de Valente, Abib e Kusnik (2006) adaptado de Souza (2001)

Assim com professores que apresentam um estilo de aprendizagem Convergente que possuem a característica a combinação da dedução e da indução para resolver problemas eles apresentam como estilo de ensino tutor que procuram ensinar as habilidades necessárias para que os problemas sejam resolvidos da melhor forma (SOUZA et al, 2013).

Outro exemplo é para os professores que possuem como estilo de aprendizagem predominante o acomodador apresentando como característica a criatividade e a facilidade de se adaptarem a novas situações, para estes têm-se o estilo de ensino inovador que buscam estimular os alunos e encorajá-los a autodescoberta, além de buscar expandir os limites intelectuais dos seus alunos esses professores devem utilizar como estratégia para suas aulas e envolver métodos e técnicas diversificadas para atender as necessidades da sua turma (SOUZA et al, 2013).

\subsubsection{Teoria da Aprendizagem Experiencial de Kolb}

David A. Kolb é doutor pela universidade de Haward formado em 1967,ganhador de quatro títulos de honorários pela sua contribuição na Aprendizagem Experiencial é também professor de Comportamento Organizacional na Escola de Weatheread de Administração, localizada nos Estados Unidos, considerado atualmente como um dos mais importantes teóricos sobre a Teoria da Aprendizagem Experiencial - TAE.

A Sua Teoria está baseada na aprendizagem experiencial que representa um processo de construção de conhecimento que envolve quatro modos de aprendizagem e se retrata em um ciclo ou em um espiral onde o aluno passa por quatro etapas que representam o agir, o pensar, o fazer e o sentir, onde a experiência imediata ou concreta é à base da observação e reflexão (KOLB E KOLB, 2005).

Com base nesse ciclo com quatro modos de aprendizagem sendo elas a Experiência Concreta, a Observação Reflexiva, a Conceituação Abstrata e a Experimentação Ativa é que 
surgem duas dimensões distintas que representam a subtração: CA-EC e EA-OR que se relacionam de forma dialética. Kolb propõe que entre a combinação CA-EC será a forma pela qual o sujeito ira captar a experiência e a combinação EA-OR será a forma de transformar a experiência (KOLB E KOLB 2005; INÊS, 2009).

\subsubsection{Inventário de Estilos de Aprendizagem de David A. Kolb}

Kolb desenvolveu o Estilo chamado de Inventário de Estilos de Aprendizagem, o Learning Inventory Styles (LSI) motivado por indagações de como se aprende melhor? Por que existem ritmos diferentes de aprendizagem? E em seu estudo ele identificou que existem formas de perceber e de processar o conhecimento, dentre essas formas ele cita: a experiência concreta, a observação reflexiva, a conceituação abstrata e a experimentação ativa. (CERQUEIRA,2000).

Para Kolb e Kolb (2005), as diferenças individuais que o sujeito possui são aplicadas nas diferentes fases do seu ciclo do Inventário de Estilos de Aprendizagem e essas diferenças são o reflexo do equipamento hereditário do ser humano, suas expectativas de vida particulares, as exigências do ambiente atual e a partir delas é possível escolher melhor entre as quatro estruturas de aprendizagem do ciclo.

Ele em seu estudo, afirma que é em resposta a esse equipamento hereditário, nossa experiência de vida particular e exigências no nosso ambiente atual é que desenvolvemos nossa maneira de aprender entre os quatro modos de aprendizagem propostos, assim, cada pessoa desenvolve seu estilo pessoal e passa por um ciclo de aprendizagem.

No ciclo surgem as duas dimensões que são combinadas entre experiência concreta versus conceituação abstrata e entre a observação reflexiva versus experimentação ativa e como resultado dessas duas combinações surgem os quatro estilos de aprendizagem e para que o ciclo se complete é necessário passar pelas quatro etapas, reiniciando-se em cada aprendizagem (KOLB E KOLB; SONAGLIO, GODOI e SILVA, 2005, 2013).

O ciclo desenvolvido por Kolb pode ser assim representado:

Figura 1 - Círculo da aprendizagem experimental de Kolb. Extraído de Experiential Learning Theory Bibliography:

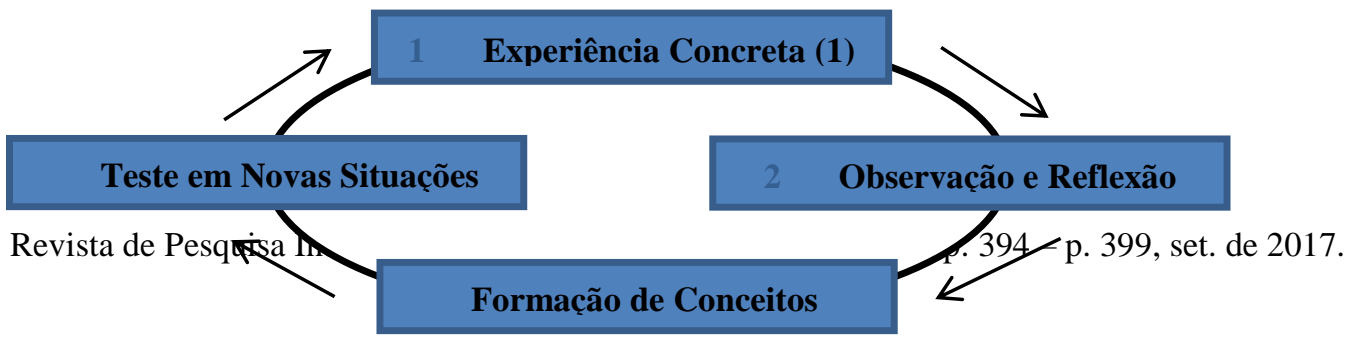


Fonte: Alice Kolb and David Kolb e disponível no site http://www.infed.org/biblio/b-explm.htm

Conforme Kolb e Kolb (2005), as principais características dos estilos de aprendizagem que identificam as preferências dos alunos de forma a estabelecer as suas questões preferidas, foram assim descritas:

- Estilo Divergente: São bons em visualizar situações concretas em diversos pontos de vista; são chamados divergentes porque são pessoas que tem melhor desempenho em situações que exigem a geração de idéias. São indivíduos que tem interesse por cultura, gostam de lidar com pessoas, tendem a ser imaginativos e emocionais, além disso, preferem trabalhar em grupo, ouvindo com a mente aberta diferentes pontos de vista.

- Estilo Assimilador: são pessoas melhores para a compreensão de uma ampla gama de informações e as colocam de forma organizada e lógica, além disso, são menos focados em pessoas e gostam mais de conceitos abstratos e idéias, gostam de teorias sólidas de valor prático, lógica. Pessoas com este estilo preferem leituras, palestras, explorando modelos analíticos, precisam ter tempo para pensar sobre as coisas.

- Estilo Convergente: os convergentes são os melhores em fazer uso prático das idéias e teorias, pois possuem grande capacidade de resolver problemas e tomar decisões; preferem lidar com tarefas técnicas e problemas, em vez de questões sociais e questões interpessoais, preferem experimentar novas idéias, simulações, trabalhos laboratoriais e aplicações práticas.

- Estilo Acomodador: São pessoas que gostam de fazer planos e se envolvem em experiências, possuem tendência em agir mais pelos sentimentos do que pela lógica na resolução de problemas. São tidos como Acomodadores por confiarem e dependerem de outras pessoas para adquirirem informações mais do que fazer uso do seu próprio julgamento e análise técnica. 


\section{PRODECIMENTOS MEDOTOLÓGICOS}

O procedimento para coleta de dados foi feito através de um questionário objetivo composto por duas seções, a primeira é a identificação do perfil do aluno e a segunda seção é o Inventário de Estilos e Aprendizagem de Kolb para identificação dos Estilos de Aprendizagem.Os dados foram classificados utilizando a seguinte soma referentes as respostas dos alunos:

Quadro 2 - Cálculo das variáveis de Kolb

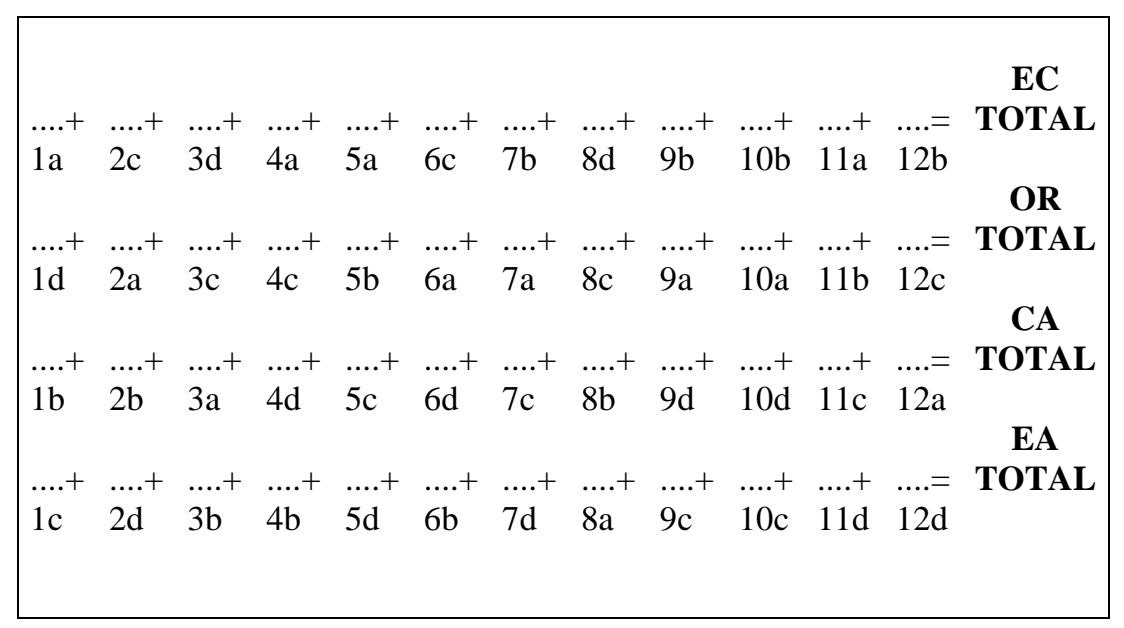

Fonte: Kolb e Kolb (2005)

Onde: $\mathrm{EC}=$ Experiência concreta $\mathrm{OR}=$ Observação Reflexiva $\mathrm{CA}=$ Conceituação Abstrata e EA = Experimentação Ativa

A presente pesquisa teve como foco os estudantes dos cursos de Administração, Ciências Contábeis e Serviço Social. O Universo da pesquisa compreendeu o total de 866 alunos matriculados em 04 Instituições de Ensino Superior às quais estão distribuídos da seguinte maneira: Universidade Federal de Campina Grande - UFCG com os cursos: Administração, Ciências Contábeis, Direito e Serviço Social; FAFIC com os cursos: Ciências Contábeis e Serviço Social; FASP e Faculdade Santa Maria, ambas com o curso de Administração. 
Dos 866 alunos do universo, 453 estão matriculados em Instituições Privadas distribuídas na FAFIC, FSM e FASP de Cajazeiras e 413 na Universidade Federal de Campina Grande, Campus de Sousa. A amostra contou com 630 alunos, mas houve a inutilização de 9 questionários por erro nas respostas, portanto o total de questionários válidos é de $621(71,71 \%)$ de toda a população.

Foi considerada como variável dependente o Coeficiente de rendimento dos alunos regularmente matriculados na época da aplicação do questionário e como variável independente os Estilos de Aprendizagem dos alunos obtidos através do Inventário de Estilos de Aprendizagem..E para que tanto o objetivo geral quanto os específicos desta pesquisa fossem alcançados foram formuladas as seguintes hipóteses:

H01: Os estilos de aprendizagem dos alunos não influenciam seu rendimento acadêmico;

H02: Os estilos de aprendizagem dos alunos influenciam seu rendimento acadêmico.

\section{RESULTADO E ANÁLISE DOS DADOS}

\subsection{Identificação dos Estilos de Aprendizagem}

Esta seção refere-se ao Inventário de Estilos de Aprendizagem de Kolb, identificando os estilos de aprendizagem dos respondentes. Os estilos de aprendizagem surgem da combinação das 4 dimensões do ciclo de aprendizagem: Experiência Concreta, Experimentação Ativa, Conceituação Abstrata e Observação Reflexiva.

Gráfico 1 -Estilos de Aprendizagem dos alunos

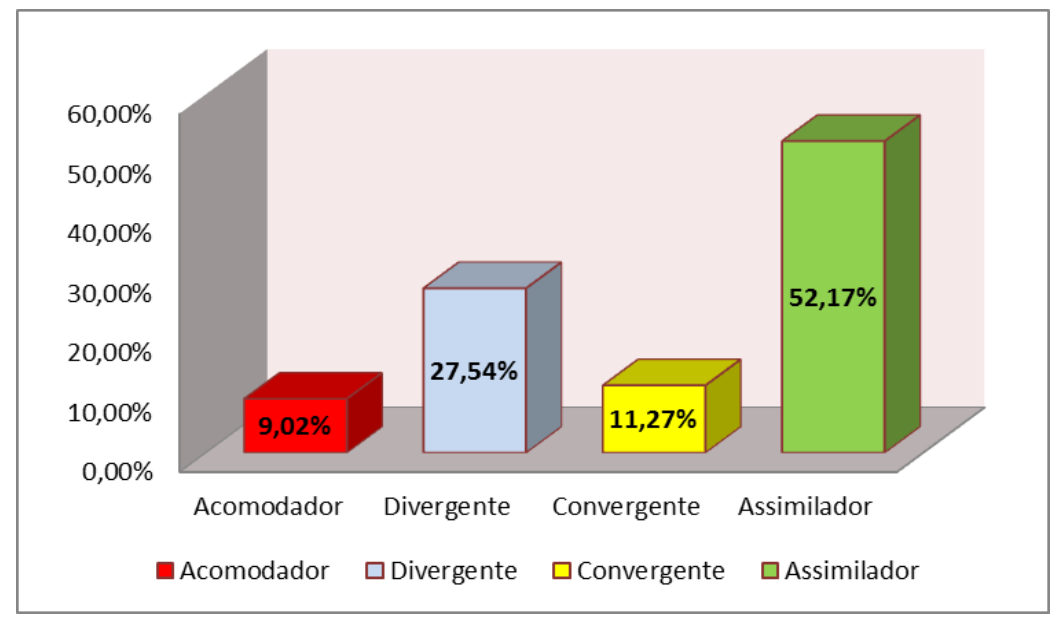

Revista de Pesquisa Interdisciplinar, Cajazeiras, n. 2, suplementar, p. 394 - p. 399, set. de 2017. 
Para os alunos que possuem a predominância do estilo Assimilador e combinam a Conceituação Abstrata (pensar) e a Observação Reflexiva (observar), gostam de criar modelos teóricos, não possuem muita preocupação com a aplicação ou utilidade prática dessas teorias, sendo importante o aprofundamento teórico.

São alunos que gostam de fazer uso da reflexão e se beneficiam quando conseguem tempo para refletir sobre o assunto, possuem habilidade em criar modelos abstratos, sobressaem-se no raciocínio analítico e os Assimiladores são menos focados em pessoas e se interessam mais por idéias e conceitos.

O gráfico 6, mostra como está distribuído o gênero dos alunos em relação aos seus estilos de aprendizagem.

Gráfico 2 - Distribuição do Estilo de Aprendizagem por gênero

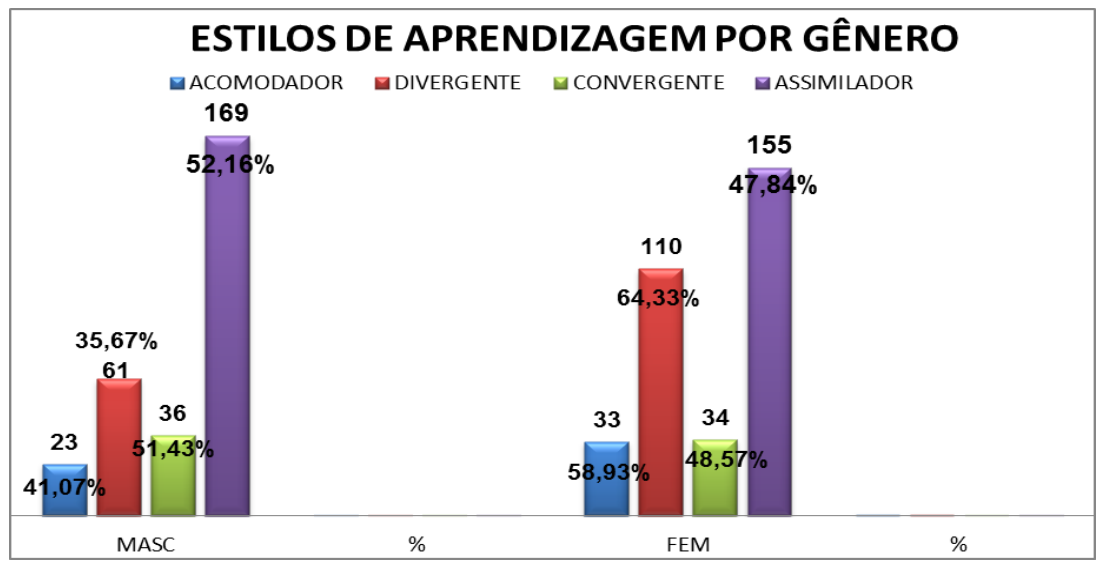

Fonte: Dados da pesquisa

Nota-se que os homens possuem maior tendência ao estilo assimilador (Pensar e Refletir) apresentando 52,16\% e no estilo Convergente (Pensar e fazer) com 51,43. O maior destaque foi para o estilo Divergente onde foi característica do gênero feminino $(64,33 \%)$, tal resultado pode estar relacionado a quantidade de alunos do sexo feminino presente no curso de Serviço Social e que foram maioria no gênero e estilo.Os Divergentes são alunos que possuem grande sensibilidade e que gostam de lidar e compreender pessoas, atuam bem frente a situações que necessitam de novas ideias (KOLB E KOLB, 2005). 
4.2 Distribuição do estilo de aprendizagem por faixa etária

Coincidindo com os resultados dos estilos de aprendizagem predominantes nos alunos desta pesquisa, o estilo Assimilador foi maioria nas 3 faixas etárias da pesquisa, conforme se observa na tabela 1.

Tabela 1 Distribuição dos estilos de aprendizagem por faixa etária

\begin{tabular}{c|c|c|c|c|c|c}
\hline \multicolumn{7}{c}{ Distribuição dos estilos de aprendizagem por faixa etária } \\
\hline & Até 21 anos & \% & $\mathbf{2 2}$ a 30 anos & \% & Acima de 30 anos & \% \\
\hline Acomodador & 23 & $41,07 \%$ & 25 & $44,64 \%$ & 8 & $14,29 \%$ \\
Divergente & 63 & $36,84 \%$ & 89 & $52,05 \%$ & 19 & $11,11 \%$ \\
Convergente & 33 & $47,14 \%$ & 29 & $41,43 \%$ & 8 & $11,43 \%$ \\
Assimilador & 141 & $43,52 \%$ & 149 & $45,99 \%$ & 34 & $10,49 \%$ \\
\hline
\end{tabular}

Fonte: Dados da pesquisa

Os resultados obtidos foram equivalentes ao resultado dos estilos de aprendizagem no geral onde predominou o estilo Assimilador e depois o Divergente, fato que se repetiu também em relação a faixa etária dos alunos e seus estilos de aprendizagem.

Após a identificação não foi constatado a predominância de nenhum estilo de aprendizagem nas três faixas etárias propostas na pesquisa, pois em todos os estilos mantiveram o maior número de alunos na mesma faixa de média, ou seja, não houve o favorecimento de nenhum estilo de aprendizagem em relação ao rendimento do aluno.

\subsection{Distribuição do estilo de aprendizagem por Instituição Pública x Privada}

A Pesquisa revelou que os alunos da Rede Privada são maioria nos estilos Acomodador e Divergente, enquanto que o Assimilador e Convergente são maioria na Pública.

Gráfico 3 - Distribuição dos Estilos por IES: Pública x Privada 


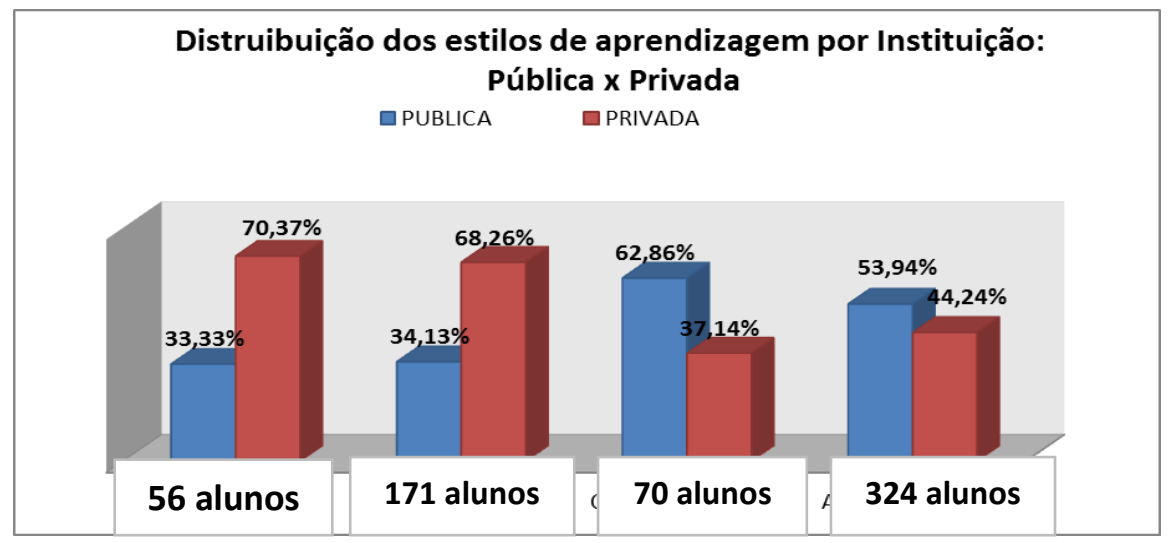

Fonte: Dados da pesquisa

Os resultados da pesquisa demonstraram conforme o gráfico 3 que os estilos Assimilador e Convergente foram maioria na Instituição Pública, mas o Divergente que do total de questionários foi o segundo em número entre os alunos apresentou maioria na Instituição Privada.

Tal fato pode estar relacionado com os tipos de curso em questão e na quantidade de alunos da amostra, pois na rede privada a maioria dos alunos do Curso de Serviço Social apresentou a maior parte dos alunos Divergentes e Acomodador que implica em maior quantidade em relação a distribuição total por IES. Já o estilo Assimilador onde a maioria são alunos de Contábeis e Administração e o maior número de alunos desses cursos estão na rede pública afetou o resultado para os Assimiladores.

A tabela 2 demonstra com maior clareza a distribuição por IES desta pesquisa.

Tabela 2. Distribuição do estilo de aprendizagem por Curso e Instituição de Ensino

\section{Universidade Federal de Campina Grande - Sousa/PB}

Acomodador Divergente Convergente Assimilador

Bacharelado em Administração

927

Graduação em Ciências Contábeis

820

16

74

Curso de Serviço Social

$1 \quad 10$

15

71

Faculdade de Filosofia, Ciências e Letras de Cajazeiras - FAFIC

$13 \quad 33$

\begin{tabular}{lcccc}
\hline & Acomodador & Divergente & Convergente & Assimilador \\
Graduação em Ciências Contábeis & 13 & 29 & 6 & 41 \\
Curso de Serviço Social & 5 & 35 & 2 & 24 \\
\hline
\end{tabular}

Faculdade Santa Maria - FSM - Cajazeiras/PB

Acomodador Divergente Convergente Assimilador 
Bacharelado em Administração 11

27

10 40

\section{Faculdade São Francisco da Paraíba - FASP}

$\begin{array}{cccc}\text { Acomodador } & \text { Divergente } & \text { Convergente } & \text { Assimilador } \\ 9 & 23 & 8 & 41\end{array}$

Bacharelado em Administração

Fonte: Dados da pesquisa.

\subsection{Distribuição do Estilo de Aprendizagem $x$ Coeficiente de Rendimento Acadêmico}

Neste estudo a variável dependente será o coeficiente de rendimento dos alunos e a independente será o estilo de aprendizagem.

O quadro a seguir detalha como está distribuída a média dos alunos em relação aos seus estilos de aprendizagem.

Quadro 3 - Distribuição do estilo de aprendizagem por média acadêmica

\begin{tabular}{|c|c|c|c|c|c|c|c|c|c|c|}
\hline & $\begin{array}{c}\text { Não } \\
\text { sabem }\end{array}$ & & 1 à 4,9 & & 5 à 6,9 & & 7 à 8,9 & & 9 à 10 & \\
\hline Acomodador & 5 & $\begin{array}{c}8,93 \\
\% \\
\end{array}$ & 1 & $\begin{array}{c}1,79 \\
\%\end{array}$ & 7 & $\begin{array}{c}12,50 \\
\%\end{array}$ & 39 & $\begin{array}{c}69,64 \\
\%\end{array}$ & 4 & $\begin{array}{c}7,14 \\
\%\end{array}$ \\
\hline Divergente & 13 & $\begin{array}{c}7,60 \\
\%\end{array}$ & 2 & $\begin{array}{c}1,17 \\
\%\end{array}$ & 20 & $\begin{array}{c}11,70 \\
\%\end{array}$ & 122 & $\begin{array}{c}71,35 \\
\%\end{array}$ & 14 & $\begin{array}{c}8,19 \\
\%\end{array}$ \\
\hline Convergente & 6 & $\begin{array}{c}8,57 \\
\% \\
\end{array}$ & 1 & $\begin{array}{c}1,43 \\
\%\end{array}$ & 14 & $\begin{array}{c}20,00 \\
\%\end{array}$ & 46 & $\begin{array}{c}65,71 \\
\%\end{array}$ & 3 & $\begin{array}{c}4,29 \\
\%\end{array}$ \\
\hline Assimilador & 25 & $\begin{array}{c}7,72 \\
\%\end{array}$ & 4 & $\begin{array}{c}1,23 \\
\%\end{array}$ & 31 & $9,57 \%$ & 243 & $\begin{array}{c}75,00 \\
\%\end{array}$ & 21 & $\begin{array}{c}6,48 \\
\%\end{array}$ \\
\hline $\begin{array}{c}\text { Total de } \\
\text { alunos }\end{array}$ & 49 & & 8 & & 72 & & 450 & & 42 & \\
\hline
\end{tabular}

Fonte: Dados da pesquisa

Após analisado o quadro 3, foi possível perceber que a média das notas permeou os valores de acima de sete e inferior a nove, destaca-se que a média para aprovação na Instituições de Ensino da pesquisa é de 7,0.

Uma vez discorrido o desempenho acadêmico dos alunos e sua distribuição pelos estilos de aprendizagem, torna-se necessário analisar a relação entre as duas variáveis propostas para que se possa responder a questão desta pesquisa. Considerando que o tópico da distribuição do rendimento acadêmico por estilos de aprendizagem já foi analisado e 
devidamente distribuído, pode-se proceder ao objetivo geral desta pesquisa identificando se a hipótese nula será aceita ou não.

Verificou-se com base nos dados da pesquisa a não rejeição da hipótese Ho1 que caracteriza que os estilos de aprendizagem dos alunos não influenciam seu rendimento acadêmico, mas que muitas vezes o baixo rendimento dos alunos pode estar relacionado a fatores emocionais, culturais, etc.

Ao observamos a distribuição por média dos alunos constatou-se que nenhum estilo de aprendizagem favoreceu os alunos em relação a sua média, pois os quatro estilos propostos por Kolb apresentou como maioria os alunos que se localizaram entre as média acima de sete e menor que nove, ou seja, não existiram indícios suficientes para constatar que os alunos se favoreceram em relação as suas preferências de estudo, este fato pode estar relacionado a metodologia de ensino dos professores de forma a abranger todos os estilos de aprendizagem de suas turmas promovendo igualdade de aprendizagem.

\section{CONSIDERAÇÕES FINAIS}

Os estilos de aprendizagem, interferem no processo educacional e necessitam ser considerados como variável que possa interferir na aprendizagem.

Alcançando os objetivos propostos para este trabalho todos os estilos de aprendizagem propostos por Kolb sejam eles: Assimilador, Acomodador, Convergente e Divergente foram identificados e em nenhum dos cursos ou Instituição, os mesmos deixaram de estar presentes demonstrando o quanto os indivíduos são diferentes em sua forma de aprender.

Quanto ao Estilo Predominante para os acadêmicos dos cursos de Administração, Ciências Contábeis e Serviço Social foi o Estilo Assimilador com 324(52,17\%) alunos que é obtido através da combinação da Conceituação Abstrata e da Observação Reflexiva.

Alunos com predominância do estilo Assimilador se baseiam fortemente no raciocínio lógico e fazendo observações e julgamentos das mesas e aprendem melhor quando são orientados por uma autoridade. Esses alunos gostam de teorias e não se preocupam com sua aplicação prática, mas sim com a teoria em si, necessitam que os professores apresentem o 
conteúdo das aulas de forma organizada e conseguem aprender apenas pela observação reflexiva, ou seja, não necessitam de uma experimentação prática do conteúdo.

Outro dado importante foi para o segundo estilo predominante na amostra Divergente que demonstrou ser mais característico de alunos do gênero feminino $(64,33 \%)$ de todos os alunos com este estilo. Caracterizado pela combinação da Experiência Concreta e Observação Reflexiva, os Divergentes são alunos voltados à análise de situações sobre diferentes perspectivas, são criativos e inovadores e considerados sentimentais, já que possuem como um dos modos de aprendizagem o sentir.

Os resultados também mostraram que em relação a Instituições de Ensino Superior, alunos da rede privada foram maioria nos estilos Acomodador e Divergente enquanto que na rede pública os estilos Assimilador e Convergente foram maioria entre as IES pesquisadas, tal fato pode estar relacionado aos Cursos, idade, gênero dos alunos ou mesmo estratégias de ensino dos professores.

Verificando se os estilos de aprendizagem impactam no rendimento acadêmico dos alunos e embora não tenha sido encontrado indício nessa pesquisa tenha ocorrido algum impacto, pois na proporção dos estilos desta pesquisa todos os alunos responderam estar na média acima de sete e menor que nove. Embora a média da maioria dos alunos seja considerada boa, tal fato não significa que o aluno realmente tenha efetivado a aprendizagem, pois outras variáveis devem ser consideradas para uma resposta mais clara a esta questão como, por exemplo,tempo dedicado ao estudo, idade, experiência profissional etc.

Dessa forma estratégias de ensino variadas podem tornar mais flexíveis os estilos de aprendizagem e uma vez mais flexível o aluno em relação aos seus estilos, o mesmo tenderá a ser mais bem sucedido seja dentro ou fora do âmbito acadêmico.

Para estudos futuros sobre os estilos de aprendizagem, sugere-se aplicação em outras instituições, inclusive na modalidade à distância, para fins de comparação.

\section{REFERÊNCIAS}

CERQUEIRA, T. C. S. Estilos de Aprendizagem em Universitários. 2000. 153f..Tese (Doutorado em Educação). Universidade Estadual de Campinas, Campinas, São Paulo. 2000. Disponível em <http://www.bibliotecadigital.unicamp.br/document/? code $=$ vtls000197620. $>$ Acesso em: 18 de jun.2014. 
COFFIELD, Frank et al. Learning styles and pedagogy in post-16 learning: A systematic and critical review. 2004.

INÊS, Rui Paulo Ramalho. A aprendizagem experiencial e a sabedoria no adulto e no adulto idoso. 2009, 312f.. (Dissertação). Faculdade de Psicologia e de Ciências da Educação Universidade de Lisboa. Disponível em http: <http://

repositorio.ul.pt/bitstream/10451/2229/1/ulsd059095_tm_Rui_Ramalho.pdf> Acesso em 16 de mar. 2015.

KOLB, Alice Y. KOLB David A. The Kolb Learning Style Inventory - Version 3.1.2005. Disponível em: <http://www.whitewater-rescue.com/support/pagepics/lsitechmanual.pdf> Acesso em 01 de jul.2014.

OLIVEIRA, Daniele Eufrásio de. Impacto dos Estilos de Aprendizagem no Desempenho Acadêmico do Ensino em Contabilidade: Uma análise dos estudantes da Universidade Federal do Rio Grande do Norte. Dissertação, Natal 2012. Disponível em: <http://repositorio.unb.br/bitstream/10482/12748/1/2012_DanieleEufrasiodeOliveira.pdf.> Acesso em: 03 de jun.2014.

SOUZA et al. 2013. Estilos de Aprendizagem dos Alunos versus Métodos de Ensino dos Professores do Curso de Administração. Artigo. Disponível em: <http://www.anpad.org.br/admin/pdf/2013_EnANPAD_EPQ16.pdf.> Acesso em: $10 \mathrm{de}$ ago.2014.

SONAGLIO, Ana Lúcia Baggio. GODOI, Christina Nekleinubing. SILVA, Anielson Barbosa. Estilos de aprendizagem experiencial e aquisição de habilidades: um estudo com discentes de graduação em administração em Instituições de Ensino Superior.2013. (Artigo). Disponível em <http://old.angrad.org.br/_resources/_circuits/article/article_1460pdf> Acesso em 25 de dez.2014.

VALENTE, Nelma Terezinha Zubek. ABIB, Diva Brecailo. KUSNIK, Luiz Fabiano. Análise dos Estilos de Aprendizagem dos Alunos e Professores do Curso de Graduação em Ciências Contábeis uma Universidade Pública do Estado do Paraná com a Aplicação do Inventário de David Kolb.2006.Dissertação disponível em <http://www.anpad.org.br/enanpad/2006/dwn/enanpad2006epqb-3161.pdf.> Acesso em: 13 de jul.2014. 